\title{
Determining the Effects of Women's Fertility Awareness Levels on Obstetric History
}

\author{
Zeliha Ozsahin $^{1(\mathbb{D}),}$ Sumeyye Altiparmak ${ }^{1(\mathbb{D})}$ \\ ${ }^{1}$ Department of Midwifery, Faculty of Health Sciences Inonu University, Malatya / Turkey. \\ Copyright@ Author(s) - Available online at https://dergipark.org.tr/en/pub/mbsjohs \\ Content of this journal is licensed under a Creative Commons Attribution-NonCommercial 4.0 International \\ License,
}

Received: 05 March 2021, Accepted: 24 April 2021, Published online: 30 April 2021

(C) Ordu University Institute of Health Sciences, Turkey, 2021

\begin{abstract}
Objective: This study was conducted using the Google Forms platform to determine the effects of women's fertility awareness on their obstetric histories.

Methods: The sample of this cross-sectional study consisted of 365 women between the ages of 18 and 49 who visited three family health centers in eastern Turkey. The data has been collected via Google Form. Data were collected using the Personal Information Form and the Fertility Awareness Scale (FAS). Descriptive statistics (n, \%, mean, standard deviation, min-max), Cronbach alpha, Pearson correlation, chi-square and independent sample t-test were used in statistical analysis.

Results: 365 women participated in the study. The women with a mean age of $34.25 \pm 6.82$ had a mean score of 38.74 \pm 6.45 in the Bodily Awareness dimension of FAS, a mean score of $32.14 \pm 5.28$ in the Cognitive Awareness dimension of FAS, a mean total score of $70.89 \pm 10.50$ in FAS, and they were determined to have a high level of fertility awareness (61.1\%). The participants' mean scores of Bodily Awareness were determined to decrease with their age of marriage and age of first childbirth $(\mathrm{p}<0.05)$. The mean FAS total and dimension scores of the women who were employed, those who had a high level of education, those who had a good economic status and those who used modern family planning methods and trust these methods were determined to be higher $(\mathrm{p}<0.05)$. The women who had sexually transmitted diseases and reproductive system infections in the past were determined to score higher, while the women who had problems during the conception process and pregnancy were determined to score lower $(\mathrm{p}<0.05)$. Among women surveyed, it was determined that miscarriage, abortion, stillbirth and having a dead child did not affect fertility awareness. Conclusion: In this study, among women surveyed, fertility awareness was observed to be affected by sociodemographic characteristics such as marriage age, first childbirth age, employment status, and economic status. It was determined that the women who used modern contraceptives and trusted these methods and the women who had sexually transmitted diseases and reproductive system infections in the past had high fertility awareness, whereas the women with low fertility awareness had health problems during the conception process and pregnancy.
\end{abstract}

Key words: Fertility awareness, Obstetric history, Women.

Suggested Citation Ozsahin Z., Altiparmak S. Questionnaire for determining the effects of fertility awareness levels of women on obstetric history., Mid Blac Sea Journal of Health Sci, 2021; 7(1):132-142

Address for correspondence/reprints:

Sumeyye Altiparmak

Telephone number: +90 (422) 377 3060/1153

E-mail: sumeyye.kandemir@inonu.edu.tr

\section{Introduction}

Fertility is defined as the ability of a person to give birth to offspring conceived during a cycle (1). It also refers to the biological characteristics of men and women who have the ability to reproduce (2). When the fertility rates in the world were examined, it was determined that the number of children decreased from 2.2 to 1.7 per woman in developed countries 
between 1970 and 2015. This rate was also found to decrease from 5.4 to 2.6 in developing countries (3).

Technological and industrial developments today not only facilitate human life but also affect our health. These developments particularly affect the fertility and reproductive systems of people (4). Technological and industrial developments bring along harmful side effects such as radiation exposure, toxic gases and pesticides. Furthermore, due to these effects, the probability of conception during a cycle (i.e., fecundity) has decreased by $7 \%$ for sexually active individuals. This decrease is estimated to continue if the necessary precautions are not taken (5). With the changing living conditions and development of technology, the age for the first conception increased globally, and the chance of having a child started to decrease gradually, due to factors such as the inclusion of educated women into the workforce, their career focus and delay in choosing a partner (6-8). In addition to the harmful effects of technological and industrial developments, there are many factors that affect fertility. These factors are advanced age, overweight, inappropriate exercise, smoking and/or alcohol consumption, excessive caffeine consumption, and mobile phone use (9-12). Furthermore, obstetric characteristics such as risky sexual behaviors, frequent and excessive number of birthing and abortion under inappropriate conditions are known to have negative effects on fertility (12). Fertility is further affected by women's lack of sufficient knowledge about these factors affecting fertility (7). Thus, providing necessary information to women about fertility and ensuring fertility protection by implementing appropriate policies is the main goal of health organizations (13). In this context, fertility awareness is emphasized, and it is desired to gain personal responsibility (12).

Awareness means having knowledge and understanding about something, while fertility awareness refers to an individual's awareness of all things related to fertility $(12,14)$. Women with fertility awareness are knowledgeable about the duration and characteristics of their menstrual cycle and the physiological effects of this cycle on their bodies. With this awareness, women are able to determine their fertile periods and decide to use contraception or not (15). It is also important to have knowledge about medical problems that affect fertility. Hormonal disorders of women causing problems such as ovulation irregularity and polycystic ovary syndrome, structural disorders in the uterus (polyps, adhesions, obstructions, etc.), endometriosis, primary ovarian failure causing early menopause, pelvic adhesions - presence of pelvic infection, postoperative abdominal or pelvic area scar tissue, and diseases such as diabetes are some medical problems that prevent fertility (12). Some negative behaviors that men and women exhibit, whether intentionally or unintentionally, may harm fertility by causing these medical problems (16). However, the fact that many negative health behaviors are modifiable, advising people on making healthy changes and raising their awareness may encourage the preservation of fertility $(12,16)$. In addition to the global increase in marriage and first childbearing ages, women's negative health behaviors increase the importance given to fertility awareness. In this direction, it is of great importance for healthcare professionals to closely follow the obstetric histories of women and diagnose and manage preventable health problems early. Additionally, preserving fertility along with changeable lifestyle behaviors will increase the chance of success in the infertility treatment process $(2,11)$. Based on this information, addressing the negative effects of fertility awareness in women on obstetric characteristics is thought to contribute to the literature. This study was conducted using the Google Forms platform to determine the effects of women's fertility awareness on their obstetric histories.

\section{Methods}

\section{Study Design and Sampling Selection}

This study was planned as a cross-sectional study to determine the effects of women's fertility awareness on their obstetric histories. Sampling, eastern Turkey between December 2020 and February 2021 three family health center was registered among women 18-49 years of age.

The inclusion criteria were as follows:

- Being sexually active,

- Having a history of at least one pregnancy,

- $\quad$ Being between the ages of 18 and 49,

- Considering having a child,

- Not having a psychiatric diagnosis.

\section{Data Collection Tools}

A Personal Information Form and the Fertility Awareness Scale (FAS) were used to collect the data.

\section{Personal Information Form}

Within the personal information form prepared by the researchers in line with the literature, there were 20 questions including the socio-demographic characteristics (age, marital status, place of residence, education and employment status, social security and 
economic status) and obstetric characteristics (number of pregnancies, number of births, family planning (FP) method used for the longest period, most trusted FP method) of the participants $(2,6,11$, 12). This form was created by the researchers using the Google Forms platform.

\section{Fertility Awareness Scale (FAS)}

The Fertility Awareness Scale (FAS) was developed by Ozsahin among Turkish women aged 18-49 in 2020 to determine the fertility awareness levels of women. The Fertility Awareness Scale is a 5-point Likert-type scale consisting of 19 items and two dimensions. These dimensions are Bodily Awareness (items 7, 9, 10, 11, 12, 13, 15, 17, 18 and 19) and Cognitive Awareness (items 1, 2, 3, 4, 5, 6, 8, 14 and 16). Items in the scale are scored from 1 to 5 (1-Never, 2-Rarely, 3-Sometimes, 4-Often and 5Always). There are no inversely scored items in the scale. The lowest possible score that can be obtained in FAS is 19, and the highest possible score is 95 . These scores are respectively 10 and 50 in the Bodily Awareness dimension and 9 and 45 in the Cognitive Awareness dimension. The level of awareness increases with the total FAS score. In evaluation of the total score obtained from FAS, a score in the range of 19-43 indicates a low awareness level, 44-69 indicates a medium awareness level, and 70-95 indicates a high awareness level. The Cronbach's alpha reliability coefficient of the scale was calculated by Ozsahin as 0.887 (12). In this study, the Cronbach's alpha reliability coefficient was found to be 0.789 .

\section{Data Collection}

Informed consent of the participants was received via Google Forms. Again, using Google Forms, data collection forms were sent to the participants and their responses were digitally collected. The data were limited to the respondents among the women who attended three family health centers. It was assumed that the answers of the participants were correct. The data collection process took approximately 5-10 minutes for each participant.

\section{Statistical analysis}

Data entry and analysis were carried out in a computer environment using the SPSS 20.0 software (Statistical Package for the Social Sciences Inc., Chicago, IL, USA). The results were evaluated in a 95\% confidence interval, and the significance level was determined as $\mathrm{p}<0.05$. The conditions for independence, randomization and quantitative data, which are parametric test assumptions, were provided. The homogeneity of variances was checked by Levene's test. It was observed that the variances in all variables were homogeneous $(p>0.05)$. The normal distribution of the data was checked with Kolmogorov-Smirnov Test. Since normal distribution was provided in the variables $(p>0.05)$, the analysis continued with parametric tests (independent-samples t-test, one-way ANOVA, Pearson's correlation analysis). Additionally, in the statistical analysis, percentage distribution, arithmetic mean, standard deviation and Cronbach's alpha were utilized.

\section{Ethical issues}

Ethical approval (Decision No: 2020/1229) of the study was obtained from the Health Sciences Scientific Research and Publication Ethics Committee of the Inonu University. The informed consent of the participants was also obtained via the internet before the study.

\section{Results}

365 women participated in the study.

The socio-demographic characteristics of the women participating in the study are presented in Table 1.The mean age of the women was $34.25 \pm 6.82$ years, the mean age of their spouses was $37.99 \pm 7.43$ years, and their mean age of marriage was $23.05 \pm 3.76$ years. Among the participants, $56.2 \%$ were unemployed, $62.5 \%$ were university graduates, $92.9 \%$ had working spouses, and $84.4 \%$ had spouses who were high school graduates. Moreover, it was determined that $77.5 \%$ of the women lived in the city center, $58.1 \%$ of them had a moderate economic status, $89.3 \%$ had a nuclear family, and the participant's mean BMI was 25.69 7.15.

The distribution of the obstetric characteristics of the women is presented in Table 2. The mean age when the women had their first child was found to be $24.19 \pm 5.51$, the women's mean total number of pregnancies was $1.76 \pm 0.42$, their mean total number of births was $1.93 \pm 1.01$, and their mean total number of children was $1.97 \pm 0.14$. It was determined that, of the family planning methods used by the women for a long time, $61.6 \%$ were modern methods, the most trusted family planning methods among $76.4 \%$ of the women were modern methods, $65.5 \%$ of the women had sexually transmitted diseases before, and $55.1 \%$ had reproductive system infections in the past. It was also found that $73.7 \%$ of the women did not have a miscarriage in the past, $80.3 \%$ did not have an abortion, $97.8 \%$ did not have a stillbirth, and $83.6 \%$ did not have a deceased child. Furthermore, it was determined that $67.9 \%$ of the women had an 
unplanned pregnancy in the past, $83.0 \%$ had no problems during conception, and $61.1 \%$ of them had no problems during pregnancy.

Table 1. The distribution of socio-demographic characteristics of women $(n=365)$

\begin{tabular}{|c|c|c|}
\hline Descriptive Properties & $\mathbf{n}$ & $\%$ \\
\hline \multicolumn{3}{|l|}{ Employment Status } \\
\hline Employed & 160 & 43.8 \\
\hline Unemployed/Housewife & 205 & 56.2 \\
\hline \multicolumn{3}{|l|}{ Educational Level } \\
\hline Literate & 6 & 1.6 \\
\hline Primary school graduate & 32 & 8.8 \\
\hline Secondary school graduate & 34 & 9.3 \\
\hline High school graduate & 65 & 17.8 \\
\hline University graduate & 228 & 62.5 \\
\hline \multicolumn{3}{|l|}{ Spouse Educational Level } \\
\hline Illiterate & 5 & 1.4 \\
\hline Literate & 2 & 0.5 \\
\hline Primary school graduate & 32 & 8.8 \\
\hline Secondary school graduate & 18 & 4.9 \\
\hline High school graduate & 308 & 84.4 \\
\hline \multicolumn{3}{|l|}{ Spouse Employment Status } \\
\hline Employed & 339 & 92.9 \\
\hline Unemployed & 26 & 7.1 \\
\hline \multicolumn{3}{|l|}{ Place of Residence } \\
\hline Province & 283 & 77.5 \\
\hline Town & 72 & 19.7 \\
\hline Village & 10 & 2.8 \\
\hline \multicolumn{3}{|l|}{ Income Status } \\
\hline Good & 130 & 35.6 \\
\hline Moderate & 212 & 58.1 \\
\hline Poor & 23 & 6.3 \\
\hline \multicolumn{3}{|l|}{ Family Structure } \\
\hline Nuclear Family & 326 & 89.3 \\
\hline Extended family & 39 & 10.7 \\
\hline \multirow[t]{2}{*}{ Total } & 365 & 100.0 \\
\hline & Mean \pm SD & \\
\hline Age (years) & $34.25 \pm 6.82$ & \\
\hline Spouse's age (years) & $37.99 \pm 7.43$ & \\
\hline Marriage age (years) & $23.05 \pm 3.76$ & \\
\hline BMI $\left(\mathrm{kg} / \mathrm{m}^{2}\right)$ & $25.69 \pm 7.15$ & \\
\hline
\end{tabular}

$\mathrm{SD}=$ Standard Deviation

The distributions of the lowest-highest scores that can be obtained from FAS and its dimensions and the lowest-highest scores and mean scores of the women are presented in Table 3.

The participants scored a minimum of 22 and a maximum of 50 points in the Bodily Awareness dimension, a minimum of 9 and a maximum of 45 in the Cognitive Awareness dimension and a minimum of 40 and a maximum of 95 in the total FAS.

The mean score obtained from the Bodily Awareness dimension was $38.74 \pm 6.45$, the mean score obtained from the Cognitive Awareness dimension was $32.14 \pm 5.28$, and the mean total score in FAS was $70.89 \pm 10.50$.

Table 4 presents the distribution of the mean scores of the participants based on their fertility awareness levels. The fertility awareness levels of the women were determined to be high $(61.1 \%)$. The women with high fertility awareness scored a minimum of 70 and a maximum of 95 points, and their mean score was $77.74 \pm 5.20$.

Table 5 presents the relationship between the women's total and subscale mean scores and their age, marriage age, first childbirth age and BMI.

It was found that the FAS total and dimension scores of the women decreased with increasing age, 
but there was no statistically significant relationship between these variables $(\mathrm{r}=-0.028, \mathrm{p}=0.589 ; \mathrm{r}=-$ $0.081, \mathrm{p}=0.124 ; \mathrm{r}=-0.058, \mathrm{p}=0.269$, respectively).

It was determined that the mean Bodily Awareness scores of the women increased significantly with increasing marriage age, there was no significant difference in terms of the Cognitive Awareness scores, and the total scale scores decreased significantly $(\mathrm{r}=0.113, \mathrm{p}=0.031 ; \mathrm{r}=0.070$, $\mathrm{p}=0.124 ; \mathrm{r}=-0.105, \mathrm{p}=0.046$, respectively). The mean Bodily Awareness scores of the women were found to increase significantly with increasing first childbirth age, but this relationship was not significant in terms of the Cognitive Awareness subscale and total scale scores $(\mathrm{r}=0.114, \mathrm{p}=0.030$; $\mathrm{r}=0.044, \mathrm{p}=0.404 ; \mathrm{r}=0.092, \mathrm{p}=0.079$, respectively).

Table 2. The distribution of obstetric characteristics of women $(n=365)$

\begin{tabular}{|c|c|c|}
\hline Obstetric Characteristics & $\mathbf{n}$ & $\%$ \\
\hline \multicolumn{3}{|c|}{ The Longest Used Family Planning Methods } \\
\hline Modern Methods* & 225 & 61.6 \\
\hline Traditional Methods ${ }^{* *}$ & 140 & 38.4 \\
\hline \multicolumn{3}{|c|}{ The Most Trusted Family Planning Methods } \\
\hline Modern Methods & 279 & 76.4 \\
\hline Traditional Methods & 86 & 23.6 \\
\hline \multicolumn{3}{|c|}{ Sexually Transmitted Disease Experiencing Status } \\
\hline Yes & 126 & 34.5 \\
\hline No & 239 & 65.5 \\
\hline \multicolumn{3}{|c|}{ Reproductive System Infection Experiencing Status } \\
\hline Yes & 164 & 44.9 \\
\hline No & 201 & 55.1 \\
\hline \multicolumn{3}{|l|}{ Miscarriage Making Status } \\
\hline Yes & 96 & 26.3 \\
\hline No & 269 & 73.7 \\
\hline \multicolumn{3}{|l|}{ Abortion Making Status } \\
\hline Yes & 72 & 19.7 \\
\hline No & 293 & 80.3 \\
\hline \multicolumn{3}{|l|}{ Stillbirth Making Condition } \\
\hline Yes & 8 & 2.2 \\
\hline No & 357 & 97.8 \\
\hline \multicolumn{3}{|l|}{ Status Having a Deceased Child } \\
\hline Yes & 60 & 16.4 \\
\hline No & 305 & 83.6 \\
\hline \multicolumn{3}{|l|}{ Unplanned Pregnancy Living Status } \\
\hline Yes & 117 & 32.1 \\
\hline No & 248 & 67.9 \\
\hline \multicolumn{3}{|c|}{ Problem Experiencing Situation During the Conceiving Process ${ }^{* * * *}$} \\
\hline Yes & 62 & 17.0 \\
\hline No & 303 & 83.0 \\
\hline \multicolumn{3}{|c|}{ Problem Experiencing Situation During the Pregnancy } \\
\hline Yes & 142 & 38.9 \\
\hline No & 223 & 61.1 \\
\hline \multirow[t]{2}{*}{ Total } & 365 & 100.0 \\
\hline & Mea & \\
\hline First Child Birth Age (years) & 24.15 & \\
\hline Total Number of Pregnancies (units) & $1.76=$ & \\
\hline Total Number of Births & $1.93=$ & \\
\hline Total Number of Children & $1.97=$ & \\
\hline
\end{tabular}

* Modern Methods: Condom, Oral contraceptive, Intrauterine Device (IUD), Injections, Subcutaneous implant

** Traditional Methods: Withdrawal, Calendar method, Breastfeeding, Methods based on fertility awareness (the length of your menstrual cycle, daily readings of your body temperature, cervical mucus)

${ }^{* * * *}$ Late conception or conceiving with treatment 
Table 3. The distribution of the lowest-highest scores that can be obtained from the FAS and its sub-dimensions, and the lowest-highest scores and the mean scores of the women $(n=365)$

\begin{tabular}{llll}
\hline Scales & $\begin{array}{l}\text { The lowest and The lowest and Mean of the } \\
\text { highest scores that } \\
\text { can be obtained }\end{array}$ & $\begin{array}{l}\text { The highest scores } \\
\text { obtained }\end{array}$ & $\begin{array}{l}\text { Mcores obtained } \\
\text { (Mean } \pm \text { SD) }\end{array}$ \\
\hline Physical Awareness Sub-dimension & $10-50$ & $22-50$ & $38.74 \pm 6.45$ \\
Cognitive Awareness Sub-dimension & $9-45$ & $18-45$ & $32.14 \pm 5.28$ \\
FAS Total & $19-95$ & $40-95$ & $70.89 \pm 10.50$ \\
\hline
\end{tabular}

FAS $=$ Fertility Awareness Scale

$\mathrm{SD}=$ Standard Deviation

Table 4. Distribution of Women's Mean Scores by Fertility Awareness Levels ( $n=365$ )

\begin{tabular}{llll}
\hline Fertility Awareness Levels & n & \% & Mean \pm SD \\
\hline Low & 4 & 1.1 & $42.25 \pm 1.50$ \\
Middle & 138 & 37.8 & $60.64 \pm 6.57$ \\
High & 223 & 61.1 & $77.74 \pm 5.20$ \\
\hline
\end{tabular}

$\mathrm{SD}=$ Standard Deviation

Table 5. The relationship between Fertility Awareness Scale total and sub-dimension mean scores of women between age, marriage age, first child birth age and BMI $(n=365)$

\begin{tabular}{|c|c|c|c|}
\hline Variables & $\begin{array}{l}\text { Physical Awareness } \\
\text { r; p }\end{array}$ & $\begin{array}{l}\text { Cognitive Awareness } \\
\text { r; p }\end{array}$ & $\begin{array}{c}\text { FAS Total } \\
\text { r; p } \\
\end{array}$ \\
\hline Age (years) & $-.028 ; .589$ & $-.081 ; .124$ & $-.058 ; .269$ \\
\hline Marriage age (years) & $.113 ; .031^{a}$ & $.070 ; .182$ & $-.105 ; .046^{a}$ \\
\hline First Child Birth Age (years) & $.114 ; .030^{a}$ & $.044 ; .404$ & $.092 ; .079$ \\
\hline BMI $\left(\mathrm{kg} / \mathrm{m}^{2}\right)$ & $-.125 ; .017^{a}$ & $-.174 ; .001^{a}$ & $-.164 ; .002^{a}$ \\
\hline
\end{tabular}

It was found that the FAS total and all dimension mean scores decreased significantly with increasing BMI scores $(\mathrm{r}=-0.125, \mathrm{p}=0.017 ; \mathrm{r}=-0.174, \mathrm{p}=0.001$; $\mathrm{r}=-0.164, \mathrm{p}=0.002$, respectively).

Table 6 presents the comparison of the FAS total and dimension mean scores of the women based on some obstetric and demographic characteristics of theirs.

It was determined that the women who used modern contraceptives for a long time and stated that the most reliable family planning methods were modern methods had significantly higher mean scores in the total FAS and both dimensions $(\mathrm{p}<0.05)$. It was also found that the women with previous sexually transmitted disease and reproductive system infection histories had significantly higher mean scores $(\mathrm{p}<0.05)$.

The FAS total and dimension scores of the women who had problems during conception and during pregnancy were found to be significantly lower $(p<0.05)$. There was no statistically significant difference for the women who had a history of unplanned pregnancy, miscarriage, abortion, stillbirth or a deceased child ( $\mathrm{p}>0.05)$.

The FAS total and dimension mean scores of the employed women were statistically significantly higher than those of the unemployed women $(\mathrm{p}<0.05)$. When the FAS total and dimension mean scores were compared based on the education levels of the participants, there was a significant difference in the Bodily Awareness dimension scores between the participants with elementary school and those with university degrees, as well as between the participants with middle school-high school and those with university degrees. There was a significant difference in the cognitive awareness dimension scores between the graduates of high school and university. There was also a significant difference between the graduates of middle school-high school and university in terms of the total mean FAS scores $(\mathrm{F}=8.517 ; \mathrm{p}=0.000 ; \mathrm{d}>\mathrm{a}, \mathrm{b} ; \mathrm{c}>\mathrm{b} ; \mathrm{F}=3.747 ; \mathrm{p}=0.000$; $\mathrm{d}>\mathrm{c} ; \mathrm{F}=7.118 ; \mathrm{p}=0.000 ; \mathrm{d}>\mathrm{a}, \mathrm{b}$, respectively).

When the FAS total and dimension mean scores of the women were compared based on their economic status, there was a statistically significant difference between those with low and middle-high economic statuses and between those with middle and high economic statuses in the Bodily Awareness dimension, whereas there was also a statistically significant difference between those with low and middle-high economic statuses in the Cognitive Awareness dimension. 
Table 6. Comparison of fertility awareness scale total and sub-dimension mean scores in terms of some obstetric and demographic characteristics of women $(n=365)$

\begin{tabular}{|c|c|c|c|}
\hline Variables & $\begin{array}{l}\text { Physical Awareness } \\
\text { Mean } \pm \text { SD }\end{array}$ & $\begin{array}{l}\text { Cognitive Awareness } \\
\text { Mean } \pm \text { SD }\end{array}$ & $\begin{array}{l}\text { FAS Total } \\
\text { Mean } \pm \text { SD }\end{array}$ \\
\hline \multicolumn{4}{|c|}{ The Longest Used Family Planning Methods } \\
\hline Modern Methods* & $39.85 \pm 5.73$ & $32.86 \pm 5.249$ & $72.72 \pm 9,71$ \\
\hline Traditional Methods ${ }^{* *}$ & $36.35 \pm 7.14$ & $31.00 \pm 5.149$ & $67.95 \pm 11.08$ \\
\hline $\mathbf{t} ; \mathbf{p}$ & 4.26; 0.000 & $3.320 ; 0.001$ & $4.31 ; 0.000$ \\
\hline \multicolumn{4}{|c|}{ The Most Family Planning Methods } \\
\hline Modern Methods & $39.70 \pm 5.79$ & $32.62 \pm 5.21$ & $72.33 \pm 9.73$ \\
\hline Traditional Methods & $35.61 \pm 7.48$ & $30.60 \pm 5.22$ & $66.22 \pm 11.5$ \\
\hline $\mathbf{t} ; \mathbf{p}$ & $5.328 ; 0.000$ & $3.132 ; 0.002$ & $4.861 ; 0.000$ \\
\hline \multicolumn{4}{|c|}{ Sexually Transmitted Disease Experiencing Status } \\
\hline Yes & $39.77 \pm 5.96$ & $33.27 \pm 5.12$ & $73.05 \pm 9.83$ \\
\hline No & $38.20 \pm 6.65$ & $31.55 \pm 5.27$ & $69.75 \pm 10.69$ \\
\hline $\mathbf{t} ; \mathbf{p}$ & $2.230 ; 0.026$ & $2.999 ; 0.003$ & $2.959 ; 0.004$ \\
\hline \multicolumn{4}{|c|}{ Reproductive System Infection Experiencing Status } \\
\hline Yes & $39.67 \pm 5.88$ & $32.76 \pm 5.10$ & $72.43 \pm 9.71$ \\
\hline No & $37.98 \pm 6.80$ & $31.64 \pm 0.39$ & $69.63 \pm 10.97$ \\
\hline $\mathbf{t} ; \mathbf{p}$ & $2.507 ; 0.013$ & $2.015 ; 0.045$ & $2.558 ; 0.011$ \\
\hline \multicolumn{4}{|c|}{ Unplanned Pregnancy Living Status } \\
\hline Yes & $38.23 \pm 6.99$ & $31.16 \pm 5.47$ & $69.42 \pm 11.26$ \\
\hline No & $38.98 \pm 6.19$ & $32.59 \pm 5.13$ & $71.58 \pm 10.07$ \\
\hline $\mathbf{t} ; \mathbf{p}$ & $-1.045 ; 0.297$ & $-2.378 ; 0.018$ & $-1.836 ; 0.067$ \\
\hline \multicolumn{4}{|c|}{ Problem Experiencing Situation During the Conceiving Process } \\
\hline Yes & $35.27 \pm 6.85$ & $29.33 \pm 5.57$ & $64.61 \pm 11.10$ \\
\hline No & $39.45 \pm 6.15$ & $32.72 \pm 5.04$ & $72.17 \pm 9.92$ \\
\hline $\mathbf{t} ; \mathbf{p}$ & $-4.781 ; 0.000$ & $-4.729 ; 0.000$ & $-5.358 ; 0.000$ \\
\hline \multicolumn{4}{|c|}{ Problem Experiencing Situation During the Pregnancy } \\
\hline Yes & $37.01 \pm 6.49$ & $30.67 \pm 5.45$ & $67.69 \pm 10.41$ \\
\hline No & $39.84 \pm 6.20$ & $33.08 \pm 4.95$ & $72.93 \pm 10.07$ \\
\hline $\mathbf{t} ; \mathbf{p}$ & $-4.177 ; 0.000$ & $-4.351 ; 0.000$ & $-4.785 ; 0.000$ \\
\hline \multicolumn{4}{|l|}{ Abortion Making Status } \\
\hline Yes & $38.55 \pm 6.57$ & $31.34 \pm 5.24$ & $69.89 \pm 10.45$ \\
\hline No & $38.81 \pm 6.43$ & $32.43 \pm 5.27$ & $71.24 \pm 10.52$ \\
\hline $\mathrm{t} ; \mathbf{p}$ & $-0.341 ; 0.733$ & $-1.742 ; 0.082$ & $-1.083 ; 0.279$ \\
\hline \multicolumn{4}{|c|}{ Status Having a Deceased Child } \\
\hline Yes & $38.18 \pm 7.15$ & $31.28 \pm 5.17$ & $69.46 \pm 10.44$ \\
\hline No & $38.85 \pm 6.3$ & $32.31 \pm 5.29$ & $71.17 \pm 10.50$ \\
\hline $\mathrm{t} ; \mathbf{p}$ & $-.737 ; 0.462$ & $-1.389 ; 0.166$ & $-1.151 ; 0.251$ \\
\hline \multicolumn{4}{|l|}{ Stillbirth Making Condition } \\
\hline Yes & $38.62 \pm 8.15$ & $29.5000 \pm 5.07$ & $68.12 \pm 11.55$ \\
\hline No & $38.74 \pm 6.43$ & $32.2073 \pm 5.27$ & $70.95 \pm 10.49$ \\
\hline $\mathrm{t} ; \mathbf{p}$ & $-0.053 ; 0.958$ & $-1.436 ; 0.152$ & $-0.753 ; 0.452$ \\
\hline \multicolumn{4}{|l|}{ Miscarriage Making Status } \\
\hline Yes & $37.70 \pm 7.05$ & $31.12 \pm 5.78$ & $68.83 \pm 11.66$ \\
\hline No & $39.00 \pm 6.29$ & $32.39 \pm 5.13$ & $71.39 \pm 10.161$ \\
\hline $\mathbf{t} ; \mathbf{p}$ & $-1.523 ; 0.129$ & $-1.840 ; 0.090$ & $-1.863 ; 0.063$ \\
\hline \multicolumn{4}{|l|}{ Employment Status } \\
\hline Employed & $39.85 \pm 5.29$ & $33.06 \pm 4.72$ & $72.86 \pm 8.72$ \\
\hline Unemployed/Housewife & $37.87 \pm 7.12$ & $31.47 \pm 5.59$ & $69.35 \pm 11.49$ \\
\hline$t ; p$ & $2.933 ; 0.004$ & $2.767 ; 0.006$ & $3.203 ; 0.001$ \\
\hline \multicolumn{4}{|l|}{ Educational Level } \\
\hline Literate & $36.83 \pm 36.83$ & $30.66 \pm 7.393$ & $67.50 \pm 17.25$ \\
\hline Primary school graduate & $36.56 \pm 36.56^{\mathrm{a}}$ & $31.62 \pm 5.434$ & $68.18 \pm 10.80^{\mathrm{a}}$ \\
\hline Secondary school graduate & $34.14 \pm 34.14^{\mathrm{b}}$ & $30.58 \pm 6.89$ & $64.73 \pm 13.38^{\mathrm{b}}$ \\
\hline High school graduate & $37.90 \pm 37.90 \mathrm{c}$ & $30.58 \pm 5.43^{\mathrm{c}}$ & $68.49 \pm 11.95^{\mathrm{c}}$ \\
\hline University graduate & $40.02 \pm 40.02^{\mathrm{d}}$ & $32.93 \pm 4.74^{\mathrm{d}}$ & $72.96 \pm 8.67^{\mathrm{d}}$ \\
\hline $\mathbf{F} ; \mathbf{p}$ & $\begin{array}{l}8.517 ; 0.000 \\
\text { d>a,b; c>b }\end{array}$ & $\begin{array}{l}3.747 ; 0.005 \\
d>c\end{array}$ & $\begin{array}{l}7.118 ; 0.000 \\
d>a b\end{array}$ \\
\hline \multicolumn{4}{|l|}{ Income Status } \\
\hline Good & $33.69 \pm 8.00^{\mathrm{a}}$ & $28.13 \pm 6.24^{\mathrm{a}}$ & $61.82 \pm 13.76$ \\
\hline Moderate & $38.02 \pm 6.49^{b}$ & $31.99 \pm 5.19^{b}$ & $70.02 \pm 10.18$ \\
\hline Poor & $40.80 \pm 5.29^{c}$ & $33.10 \pm 4.90^{\mathrm{c}}$ & $73.91 \pm 9.18$ \\
\hline $\mathbf{F} ; \mathbf{p}$ & $16.211 ; 0.000$ & $9.290 ; 0.000$ & $15.862 ; 0.000$ \\
\hline & $\mathbf{c}>\mathbf{b}>\mathbf{a}$ & $\mathbf{c}>\mathbf{b}>\mathbf{a}$ & $\mathbf{c}>\mathbf{b}>\mathbf{a}$ \\
\hline Place of Residence & & & \\
\hline Province & $39.103 \pm 9.10^{\mathrm{a}}$ & $32.21 \pm 5.15$ & $71.31 \pm 10.12$ \\
\hline Town & $38.12 \pm 7.13^{\mathrm{b}}$ & $32.00 \pm 5.53$ & $70.12 \pm 11.30$ \\
\hline Village & $33.00 \pm 7.91^{\mathrm{c}}$ & $31.40 \pm 7.29$ & $64.40 \pm 13.76$ \\
\hline $\mathbf{F} ; \mathbf{p}$ & $\begin{array}{l}4.828 ; 0.009 \\
a, b>c\end{array}$ & $0.149 ; 0.862$ & $2.350 ; 0.097$ \\
\hline
\end{tabular}

$\mathrm{t}=$ Independent simple $\mathrm{t}$ test $\mathrm{F}=$ One-way anova test,

* Modern Methods: Condom, Oral contraceptive, Intrauterine Device (IUD), Injections, Subcutaneous implant

** Traditional Methods: Withdrawal, Calendar method, Breastfeeding, Methods based on fertility awareness (the length of your menstrual cycle, daily readings of your body temperature, cervical mucus)

***In the Anova Test, The Duncan Test, one of the post-hoc pairwise comparison tests, was used for pair group comparisons. 
There was also a statistically significant difference between those with low and middle-high economic statuses and between those with middle and high economic statuses in terms of their total mean FAS scores $(\mathrm{F}=16.211 ; \quad \mathrm{p}=0.000 ; \quad \mathrm{c}>\mathrm{b}>\mathrm{a} ; \quad \mathrm{F}=9.290$; $\mathrm{p}=0.000 ; \quad \mathrm{c}>\mathrm{b}>\mathrm{a} ; \quad \mathrm{F}=15.862 ; \quad \mathrm{p}=0.000 ; \quad \mathrm{c}>\mathrm{b}>\mathrm{a}$, respectively).

When the FAS total and dimension mean scores of women were compared based on their place of residence, there was a significant difference between those living in villages and districts and those living in the city center in the Bodily Awareness dimension scores, while there was no significant difference in terms of place of residence in the Cognitive Awareness dimension scores ( $\mathrm{F}=4.828 ; \mathrm{p}=0.009$; $\mathrm{a}, \mathrm{b}>\mathrm{c} ; \quad \mathrm{F}=0.149 ; \quad \mathrm{p}=0.862 ; \quad \mathrm{F}=2.350 ; \quad \mathrm{p}=0.097$, respectively).

\section{Discussion}

The findings obtained from this study which was conducted to determine the effects of the fertility awareness levels of women on their obstetric history are discussed in this section in accordance with the relevant literature. Postponement of having children is caused by many personal, social and economic factors (6-8). This actually shows that planning pregnancy or using contraception is not always an informed action (17). For this reason, all women of reproductive age should get information about factors such as the appropriate time to conceive, using contraception and modifiable issues affecting fertility (age, sexually transmitted diseases, BMI) $(8,17)$. Preventable risk factors are emphasized for the protection and care of fertility in high-income countries (18). Fertility care may be provided by increasing fertility awareness via emphasizing preventable risk factors (18).

In this study, $61.1 \%$ of the women were found to have a high level of fertility awareness (Table 4). Furthermore, while the rate of the women with moderate fertility awareness levels was $37.8 \%$, the rate of those with low fertility awareness levels was $1.1 \%$ (Table 4). Besides this, in the literature, it is seen that the fertility awareness levels of women have been reported to be low or moderate $(7,16)$. The finding in this study that the rate of the women with low fertility awareness levels was not compatible with the literature may be associated with the fact that the vast majority of the participants in this study were university graduates. When it comes to fertility awareness, the first thing that comes to mind is planning or postponement of having a child. Fertility awareness also requires bodily awareness (frequent pregnancies, abortions, advanced maternal age, sexually transmitted infections, reproductive system infections, and their harm to fertility) (19-21), as well as cognitive awareness, as in recognizing the symptoms of the individual's own body (22). In this study, the mean Cognitive Awareness dimension score of the women was found as $32.14 \pm 5.28$, whereas their mean Bodily Awareness dimension score was $38.74 \pm 6.45$ (Table 3). In a study, participating women with low fertility awareness levels were found to not have enough information about their fertile periods and be misinformed (23). However, it was also stated that, with effective counseling, women may get to know their bodies, and their cognitive knowledge could increase $(17,23)$. In this study, fertility awareness was found to be a variable associated with a negative obstetric history. For example, it was found that the mean score of bodily awareness decreased with decreasing ages of marriage and first childbearing (Table 5). It is understood that women who marry at a young age do not know their bodies well. Women who do not know their bodies well and use natural family planning methods experience more anxiety about unwanted pregnancies (24). Studies have shown that the education levels of women with a younger age of marriage and a younger age of first childbearing are lower (25-27). It was a similar finding to the literature in this study that, as the age of marriage and first childbearing in the participating women decreased, their mean Bodily Awareness scores decreased (Table 5). What is more, there was a statistically significant negative correlation between BMI and FAS total and dimension scores (Table 5). BMI was observed to increase as the fertility awareness mean scores of the women decreased. In a study, it was found that individuals with a high level of education paid more attention to their nutrition (28). Studies have demonstrated that the need for training increases with increasing BMI (28-30). The negative relationship between the BMI and fertility awareness levels observed in this study was consistent with the literature and showed that women with low fertility awareness levels have higher BMI.

The World Health Report states that unwanted pregnancies are among the most common causes of maternal deaths in developing countries (31). The failure to use family planning methods effectively is the culprit in this issue $(32,33)$. Although most women are aware of modern and natural family planning methods, they have insufficient knowledge about details such as protection periods, return of fertility when these methods are stopped and benefits of methods other than contraceptives (33). In this regard, it is essential to increase the awareness levels 
of women. The total FAS scores and the mean Bodily Awareness and Cognitive Awareness dimension scores of the women who stated that the FP method they used the longest and the most reliable FP method were "modern methods" (Table 6) were higher. This finding indicated that women with high fertility awareness levels use modern contraceptive methods more.

The result that the women with a history of a sexually transmitted diseases or reproductive system infections had higher levels of fertility awareness was a striking finding of this study (Table 6). It may be argued that a history of infection increases the importance of fertility awareness for women, and the bodily and cognitive awareness of women increases after such a negative experience. Reproductive system infections are among the most common health problems faced by women (34). Infections in the reproductive organs may prevent conception or the healthy continuation of a pregnancy. It is stated that most women need education and counseling for preventing reproductive system infections (34). Especially considering the negative consequences of sexually transmitted diseases, it is essential to increase the awareness levels of women on this issue. From this point of view, it may be concluded that fertility awareness is a significant variable in terms of sexually transmitted diseases and reproductive system infections.

In this study, the mean age of the participating women was found to be $34.25 \pm 6.82$ (Table 1). Considering "planning to have a child", which was one of the criteria of this study, it may be seen that the age of becoming a mother had advanced. It is seen worldwide that the age of maternity is being postponed. Advanced maternal age is associated with lowering the chance of having the desired number of children (8), low-quality follicles, prolonged conception, abortion and increased obstetric diseases (17). In a study, it was stated that the possibility of conception decreased with increasing age for women (35). Women need to be informed about the consequences of advanced maternal age $(8,36)$. Therefore, advanced maternal age should be taken into consideration in pregnancy planning and counseling (37). According to Turkish Statistical Institute 2019 data, the rate of women who graduated from high school or faculty is $18.5 \%$ (38). In this study, the rate of women who graduated from high school or faculty is $62.5 \%$. The difference between the findings is striking. The fact that the Google Forms method was used in this study may have resulted in reaching more university graduate women and limited number participant. When the fertility awareness mean scores of the participants were compared based on their descriptive characteristics, it was found that the relationship between their employment status, economic status and education levels and their scale total and dimension mean scores was statistically significant (Table 6). The mean total fertility awareness scores and the mean dimension scores of the women who were employed, those who had higher education levels and those who had a good economic status (Table 6) were found to be higher. Furthermore, it was found that the mean bodily fertility awareness score of the women living in the city center was higher than those living in villages and districts. When the literature is examined, it may be observed that place of residence, education level and economic status are among the significant factors that affect women's contraceptive preference, marriage age and their risk of having an STD and/or a reproductive system infection $(21,32,39)$. Beekle and $\mathrm{McCabe}$ found that contraceptive preference was affected by the sociodemographic characteristics of women. Salari et al. reported that women living in rural areas are in need of increasing their fertility awareness $(21,32)$. Dogru et al. determined that education level is effective in the choice of a contraceptive method. These results have shown that the findings of this study were compatible with the literature $(21,32,40)$.

\section{Conclusion}

In this study, among women surveyed, fertility awareness levels were determined to be affected by their age of marriage, age of first childbearing, employment status, and economic status. The women who were employed, those who had a higher education level and those who had a good economic status were observed to have a higher Bodily and Cognitive awareness subscale mean scores. Midwives and other healthcare professionals should take into account the sociodemographic and obstetric characteristics of women while considering reproductive planning in meetings with women of reproductive age.

\section{Limitation}

As this study was carried out with women living in eastern Turkey, its results may not be generalized to the entire society. The small sample size of the study was another limitation. Additionally, the fact that the study was conducted using the Google Forms platform led more university and high school graduate women to respond to the data collection forms. This situation may prevent one from making a 
comment on the fertility awareness levels of women with low educational levels.

Ethics Committee Approval: Ethical approval (Decision No: 2020/1229) of the study was obtained from the Health Sciences Scientific Research and Publication Ethics Committee of the Inonu University. The informed consent of the participants was also obtained via the internet before the study.

Peer-review: Externally peer-reviewed.

Author Contributions:

Concept: ZÖ.; Design: Z.O, S.A, Literature Search: Z.O, S.A, Data Collection and Processing: Z.O, S.A Analysis or Interpretation: Z.O, S.A; Writing: Z.O, S.A

Conflict of Interest: No conflict of interest was declared by the author.

Financial Disclosure: The author declared that this study hasn't received no financial support.

\section{Acknowledgements}

We would like to thank the women who participated and completed this questionnaire.

\section{References}

1. Zegers-Hochschild F, Adamson GD, Dyer S, Racowsky, de Mouzon J, Sokol R, et. al. The international glossary on infertility and fertility care. Fertility and Sterility. 2017;108(3): 393-406.

2. Aksoy Derya Y. Healthy Lifestyle Behaviours Protectıng Fert1lity. In: Efe R, Sancar B. (eds). Recent Developments in Nursing and Midwifery. 2018:603-12.

3. United Nations, Department of Economic and Social Affairs, Population Division. World Fertility Patterns 2015 - Data Booklet (ST/ESA/SER.A/370), 2015. (Date of Access: 20 February 2021).

4. Fleming TP, Watkins AJ, Velazquez MA, Mathers JC, Prentice AM, Stephenson J, et. al. Preconception health 2 Origins of lifetime health around the time of conception: causes and consequences. Lancet. 2018;391(10132):184252.

5. Alamo A, Condorelli RA, Mongioì LM, Cannarella R, Giacone F, Calabrese V, et. al. Environment and male fertility: Effects of benzo$\alpha$-pyrene and resveratrol on human sperm function in vitro. J Clin Med. 2019;8(4):561.

6. Silvestris E, Lovero D, Palmirotta R. Nutrition and female fertility: An Interdependent correlation. Front Endocrinol (Lausanne). 2019;10:1-12.
7. Mahey R, Gupta M, Kandpal S, Malhotra N, Vanamail P, Singh N. Fertility awareness and knowledge among Indian women attending an infertility clinic: A cross-sectional study. BMC Womens Health. 2018;18(177):1-7.

8. Delbaere I, Verbiest S, Tydén T. Knowledge about the impact of age on fertility: A brief review. Ups J Med Sci. 2020, 125(2):167-74.

9. Hammarberg K, Setter T, Norman RJ, Holden CA, Knowledge about factors that in fluence fertility among Australians of reproductive age: A population-based survey. Fertil Steril. 2019;99(2):502-7.

10. Reynolds RM, Gordon A. Obesity, fertility and pregnancy: Can we intervene to improve outcomes? J Endocrinol. 2018;239:47-55.

11. Altiparmak S, Aksoy Derya Y. The effects of fertility-supporting health training on healthy lifestyle behaviors and infertility self-efficacy in infertile women: A quasi-experimental study. Eur J Integr Med. 2018;20:146-53.

12. Ozsahin $Z$. The effect of training given in line with the health promotion model aimed at increasing fertility awareness on fertility awareness in women. Malatya: Inonu University Health Sciences Institute. 2020.

13. Ilacqua A, Izzo G, Emerenziani G, Pietro, Baldari C, Aversa A. Lifestyle and fertility: The influence of stress and quality of life on male fertility. Reprod Biol Endocrinol. 2018;16(115):1-11.

14. Fertility Awareness: Natural Family Planning (NFP) http://americanpregnancy.org/ preventingpregnancy/natural-family-planning. (Date of Access: 20 February 2021).

15. Sansone A, Sansone M, Vaamonde D, Sgrò P, Salzano C, Romanelli F, et. al. Sport, doping and male fertility. Reprod Biol Endocrinol. 2018;16(114):1-12.

16. Harper J, Boivin J, Neill HCO, Brian K, Dhingra J, Dugdale G, et. al. The need to improve fertility awareness. Reprod Biomed Soc Online. 2017;4:18-20.

17. Pedro J, Schmidt L, Costa ME, Martins MV. What do people know about fertility? A systematic review on fertility awareness and its associated factors. Upsala Journal of Medical Sciences. 2018;123(2):71-81. https://doi.org/10.1080/03009734.2018.1480186

18. Bayoumi RR, Van Der Poel S, El Samani EZ, Boivin J. An evaluation of comprehensiveness, feasibility and acceptability of a fertility awareness educational tool. Reproductive biomedicine and society online. 2018;6: 10-21. https://doi.org/10.1016/J.Rbms.2018.06.003 
19. Barazani Y, Katz BF, Nagler HM, Stember DS. Lifestyle, Environment, and male reproductive health. Urologic Clinics Of North America. 2014;1(1), 55-66.

20. Johnson HL, Ghanem KG, Zenilman JM, Erbelding EJ. Sexually transmitted infections and adverse pregnancy outcomes among women attending inner city public sexually transmitted diseases clinics. Sexually Transmitted Diseases 2011;38(3):167-171.

Https://doi.org/10.1097/Olq.0b013e3181f2e85f

21. Salari R, Salari R, Medicine C. Electronic physician (Issn: 2008-5842). Electronic Physician. 2017; 9(1):3592-3597.

22. Family Planning-A global handbook for providers. 2018 edition. Available from: https://www.who.int/reproductivehealth/publicati ons/fp-global-handbook/en/ (Date of Access: 25 January 2021).

23. Hampton K, Mazza D. Attitudes and practices of women attending general practice. Reprınted From Afp. 2015;44(11): 840-845.

24. Fehring RJ, Schneider M, Raviele K, Rodriguez D, Pruszynski J. Randomized comparison of two internet-supported fertility-awareness-based methods of family planning. Contraception. 2013;88(1), 24-30.

25. Aktepe E, Atay İM. Child marriages and psychosocial consequences. Current Approaches İn Psychiatry. 2017;9(4): 410-410. https://doi.org/10.18863/Pgy.310791

26. Eren GT. Socio-Cultural basis of marriage thoughts of women experiencing early marriage: Ardahan example. Ankara: Hacettepe University Social Sciences Institute. 2017.

27. Tuna Uysal M, Tan Eren G, Simsek E. Naturalization of the social: Gender perception in early marriages. Suleyman Demirel University Faculty of Arts and Sciences Journal of Social Sciences. 2019;1(47), 196-220. https://doi.org/10.35237/Sufesosbil.569738

28. Kayisoglu S, Icoz A. The effect of education level on fast-food consumption habit. Journal of Tekirdag Faculty of Agriculture. 2012; 16-19.

29. Basaran Dursun H, Yllmaz E. Learning Requirements of Patients Undergoing Abdominal Surgery. Celal Bayar University Journal of Health Sciences Institute. 2015;2(3), 65-70.

30. Gor A, Beyaz FB, Koc PAA. Prevalence and socioeconomics determinants of adults obesity in Antalya. Journal of Akdeniz F.E.A.S. 2011; (21): $17-45$.
31. World Health Report. (2005). Make Every Mother And Child Count. https://www.who.int/whr/2005/en/ (Date of Access: 20 February 2021).

32. Beekle AT, Mccabe C. Awareness And Determinants Of Family Planning Practice İn Jimma, Ethiopia. International Nursing Review 2006;53(4), 269-276. https://doi.org/10.1111/J.14667657.2006.00492.X

33. Tuladhar M. Awareness and practice of family planning methods in women attending gyne opd at Nepal Medical College Teaching Hospital. Nepal Medical College Journal. 2008;10(3):184-191. https://Pubmed.Ncbi.Nlm.Nih.Gov/19253864/

34. Aktas D, Sahin E, Gonenc IM. Some common gynecological problems and nursing approaches affecting women's health. Ankara Journal of Health Sciences. 2012;1(2):037-053. https://doi.org/10.1501/Asbd_0000000017

35. Kaplan B, Nahum R, Yairi Y, Hirsch M, Pardo J, Yogev Y, et. al. Use of various contraceptive methods and time of conception in a communitybased population. European Journal of Obstetrics and Gynecology and Reproductive Biology. 2005; 123(1),72-76. https://doi.org/10.1016/J.Ejogrb.2005.06.033

36. Balasch J, Gratacós E. Delayed childbearing: Effects on fertility and the outcome of pregnancy. Fetal Diagnosis and Therapy. 2011;29(4):263-73. https://doi.org/10.1159/000323142

37. Daniluk JC, Koert E, Cheung A. Childless women's knowledge of fertility and assisted human reproduction: Identifying the gaps. Fertility and Sterility. 2012;97(2):420-26. https://doi.org/10.1016/J.Fertnstert.2011.11.046

38. Turkish Statistical Institute 2020. https://tuikweb.tuik.gov.tr/PreHaberBultenleri.do ?id=37221(Date of Access: 08 April 2021)

39. Journal DM. The overview of women by age groups on the family planning and the evaluation of preferred methods: A tertiary center experience. Dicle Medical Journal. 2016; 43(3), 413-418. https://doi.org/10.5798/Diclemedj.0921.2016.03. 0706

40. Dogru HY, Oktay G, Isguder CK, Ozsoy AZ, Cakmak B, Delibas IB, et. al. The overview of women by age groups on the family planning and the evaluation of preferred methods: A Tertiary center experience. Dicle Medical Journal, 2016;43(3): 413-8. 